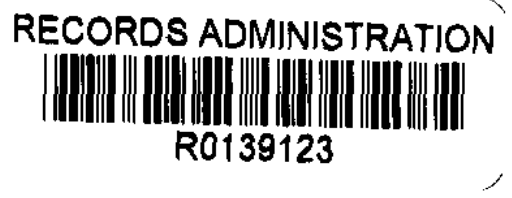

DP-1534

TIS FILE

RECORD COPY

\title{
PULSE HEIGHT ANALYZER/OSCILLOSCOPE DISPLAY INTERFACE
}

W. J. WOODWARD, JR.

OCTOBER 1979

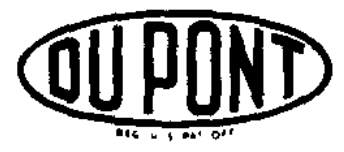

E. I. du Pont de Nemours \& Co. (Inc.) Savannah River Plant and Laboratory Aiken, South Carolina 29801 
This report was prepared as an eccount of work eponsored by the United Btotes Government. Nelther the United States nor the United Stetes Do. partment of Eneroy, nor eny of thelr employeas, make eny warranty. ix. prece or Implied, or enumes any leal liability or remponulbillty for the sccuracy, completenose; or uwituiness af any information, apparetus, produet, or procest dieclowed, or ropreante that its us would not infringte privately owned rights. Roference herein to any seclfic commercial pro. duct, procuse or service by trede nems, mark, manufecturer, or ostherwies. does not necesually constitute or imply its endorament, recommundation, of fevoring by the United Stetes Government or any coency thereot. The vlewe and opinions of euthors exprosed herein do not necesearily stete or reflect thow of the United Stives Government or any epency theriof.

Printed in the United States of America Available from

Netional. Thennicul Jafoxmation Services

U. S. Department of Commerce

5285 Port Royal Road

Springtield, Vireinia 22161

Price: Printed Copy A02; Microfiche AO1 


\section{PULSE HEIGHT ANALYZER/OSCILLOSCOPE DISPLAY INTERFACE}

W. J. WOODWARD, JR.

Approved by

D. BAKER, JR., RESEARCH MANAGER

LABORATORY OPERATIONS AND SERVICES

OCTOBER 1979

Issued by E. I. du Pont de Nemours \& Co. (Inc.) Savannah River Laboratory Aiken, South Carolina 29801

PREPARED FOR THE U. S. DEPARTMENT OF ENERGY UNDER CONTRACT DE-AC09-76SR00001 
ABSTRACT

A portable interfacing instrument was developed that accepts digital information from a pulse height analyzer and displays it as an energy spectrum on an ordinary laboratory oscilloscope. 


\section{CONTENTS}

Introduction 4

Component Selection 4

Pulse Height Analyzer Mercury Access 5

Horizontal Display 5

Vertical Display 8

Batteries 10

Performance of the Interface Device 10

References $\quad 12$

\section{LIST OF FIGURES}

1 Instrument Front Pane1 6

2 PHA/Oscilloscope Interface, Simplified Block Diagram 7

3 Demultiplexer-DAC, Simplified Program 9

4 Instrument with Battery Charger Connected 11 


\section{A PULSE HEIGHT ANALYZER/OSCILLLOSCOPE DISPLAY INTERFACE}

\section{INTRODUCTION}

A 4096-channel Pulse Height Analyzer (PHA) and a Microprocessor-based Controller were developed at the Savannah River Laboratory. ${ }^{1,2}$ An energy spectrum stored in a memory array in the PHA may be read out as 4096 binary words, each 20 bits long. A11 or part of this spectrum would best be displayed in graphic form as discrete energy levels on the horizontal axis versus total number of events at each level on the vertical axis. Ordinary laboratory oscilloscopes are available for this type display, therefore an instmument was developed to convert the digital PHA data to the required oscilloscope input signals.

\section{Initial design requirements were:}

1. The device must be portable, and therefore light weight, a convenient size, and battery-operated. (rechargeable batteries would be preferred.)

2. Vertical display must be linear, the analog equivalent of 10 successive binary bits, and range selectable from the 10 least significant through the 10 most significant bits in 6 steps.

3. Horizontal display must be linear, include 4096 channe1s (or less, as desired), and be a function of the timed sweep of the oscilloscope.

\section{COMPONENT SELECTION}

The design requirements dictated the choice of most of the system components. Some are listed below:

1. COS/MOS (Complimentary-symmetry, meta1-oxide semiconductor) logic for its low power consumption.

2. Sealed lead-acid, gelled-electrolyte batteries for their capacity, charge-discharge characteristics, and convenient voltage ratings.

3. Wire-wrapped logic boards for their ease of plugging in dual in-line packaged (DIP) chips, headers, and extra-board ribbon cable connectors. 
4. An aluminum attache-sized case for its ease of handing, light weight, and durability.

The choice of COS/MOS logic influenced the selection of the Digita1-to-Analog Converter (DAC). In addition to COS/MOS compatibility, the DAC must have good resolution and linearity plus a settling time fast enough to convert 4096 data words in a single oscilloscope sweep where the sweep repeats rapidly enough to provide a flicker-free display. Analog Devices' mode1 AD 7520 meets these requirements, will operate from a single 5 to $15 \mathrm{~V}$ power supply and dissipates only $20 \mathrm{MW}$ or power. Output is derived from a separate reference voltage divided via a switched $R-2 R$ ladder network. The DAC is a 10-bit unit, of which the least significant bit represents less than $0.1 \%$ of full scale. Therefore, readability on an oscilloscope screen will not suffer even when the 10 bits converted are the most significant of the 20 available for display.

\section{PULSE HEIGHT ANALYZER MEMORY ACCESS}

The PHA memory is arranged so the 4096 locations, or addresses can be accessed serially when using the "DISPLAY" operating mode. A train of 4096 evenly-spaced pulses may be fed to an address scaler to generate 4096 12-bit addresses. These are applied sequentially to the 20 memory chips $(4096 \times 1$ bit each), each of which goes to a readout buffer. The squarewave pulse train causes the address scaler to advance on each rising edge. New data is latched into the buffers approximately 1 usec after each falling edge. Thus, 4096 words are presented serially at the buffer outputs (20 1ines), each word a 20-bit binary number.

\section{HORIZONTAL DISPLAY}

A $250 \mathrm{KHZ}$ clock frequency was chosen to operate the readout logic because of the 1 usec data switching time of the memory, the $500 \mathrm{nsec}$ settling time of the DAC, and the sweep time of approximately $16 \mathrm{msec}$ for 4096 channels. This requires a sweep repetition rate of a little less than $60 \mathrm{~Hz}$, which yields a flicker-free oscilloscope trace. The $250 \mathrm{KHz}$ pulse train is easily obtained by counting down from the $4 \mathrm{MHz}$ clock frequency in the PHA, and is presented to the interface as a square wave between high and low logic levels - a continuous train of pulses $2 \mu \mathrm{sec}$ wide and $2 \mu \mathrm{sec}$ apart.

The portion of the instrument panel (Fig. 1) marked "SCOPE DISPLAY" contains the mode switch and two 4-decade digital thumb-wheel switches (Fig. 2). On the panel, the mode switch is marked "HORIZONTAL." When in the "SET UP" position, the mode 


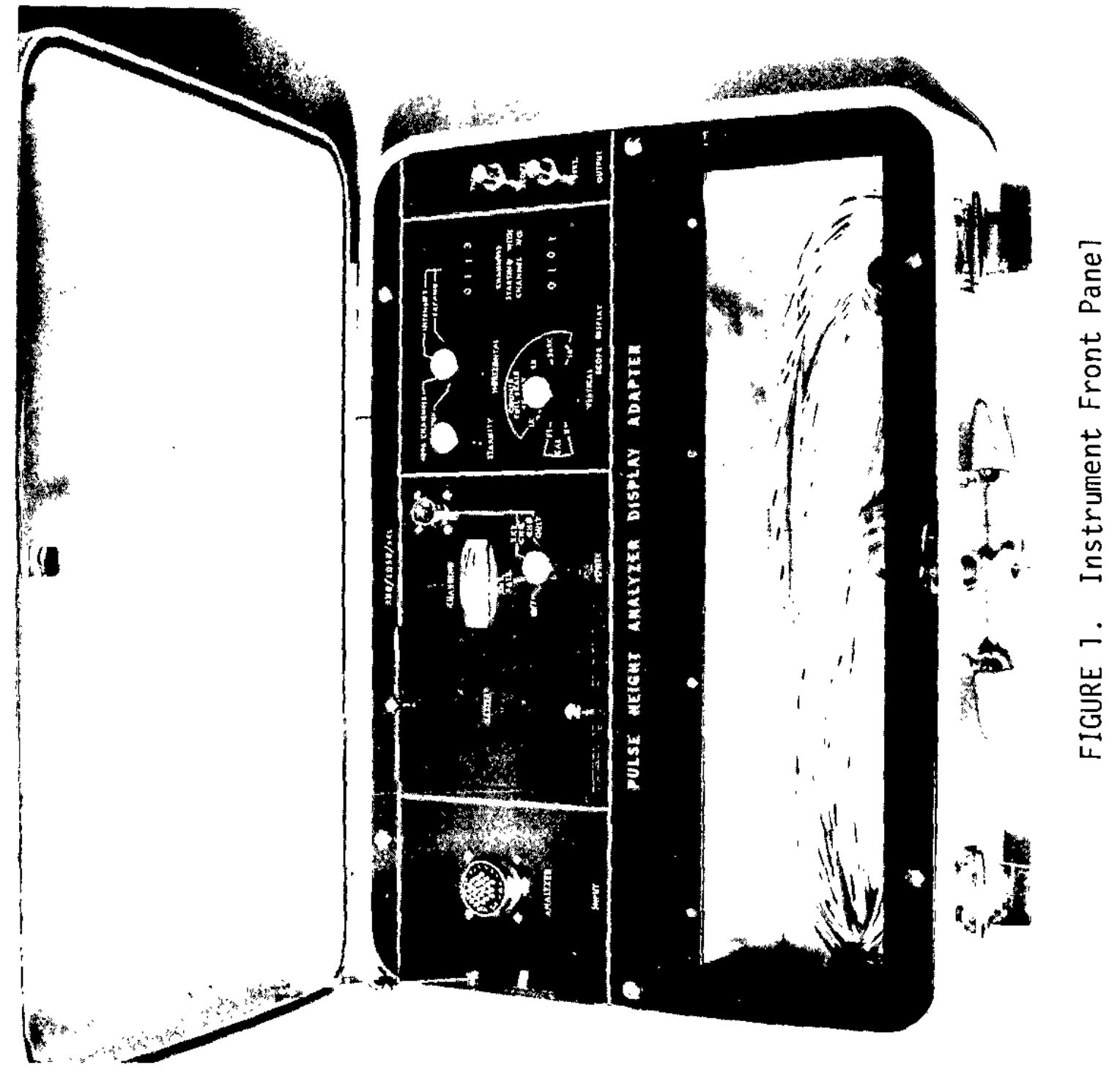




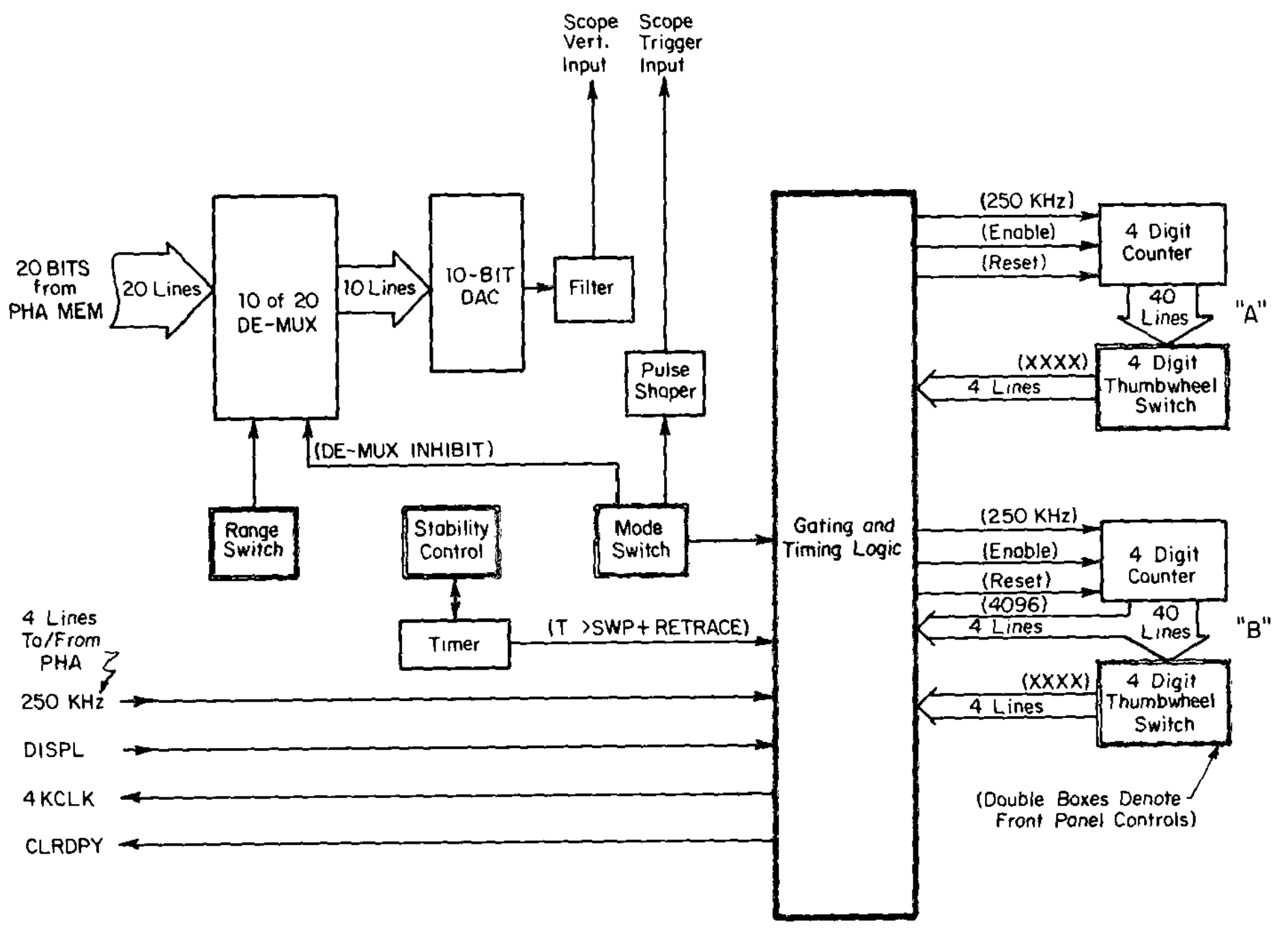

FIGURE 2. PHA/0scilloscope Interface, Simplified Block Diagram 
switch selects gating and timing logic to enable a 4-digit counter ("B") to count the $250 \mathrm{KHz}$ clock pulses until 4096 have been registered, at which time the counter is disabled. 4096 pulses are gated out ( 4 KCLK) to the PHA and the scope vertical input simultaneously. The scope sweep is triggered at the beginning of $4 \mathrm{KCLK}$. The operator may use this display to adjust the scope's sweep controls so that the 4096 pulses just fill the desired portion of the screen. A timer in the interface is started when the scope is triggered, and the time may be adjusted to allow for full sweep and retrace, after which the process is repeated. The timer adjustment is marked "STABILITY," and is used to eliminate display flicker. The PHA address scaler is reset after the $4096 \mathrm{th}$ pulse via the clear display (CLRDPY) 1ine; counter " $B$ " is reset at the same time.

The same gating/timing action takes place when the mode switch is in the "4096 CHANNELS" position, except that the scope vertical input is connected to the analog output of the DAC instead of $4 \mathrm{KCLK}$.

Positions 3 and 4 of the mode switch bring the digital thumbwheel switches into play. Panel markings read "INTENSIFY (or EXPAND) XXXX CHANNELS STARTING WITH CHANNEL NO. XXXX, where $X X X X$ is a 4-digit decimal number set up on the thumb-wheels by the operator. The "INTENSIFY" position allows display of a11 4096 channels (sweep triggered as before), but the demultiplexer outputs are inhibited for portions of alternate sweeps. On odd-numbered sweeps analog output is zero from channel " $O$ " through the number set up for counter "B", normal for XXXX (B) through [XXXX (b) $+\operatorname{XXXX~(A)],~then~zero~again~}$ through channel 4095. On even-numbered sweeps analog output is normal from 0 through 4095 . The display intensity may be adjusted so that a difference in intensity and flicker is noticeable between the region of interest and the remainder of the sweep. This allows the operator to locate a peak in the spectrum by using the thumbwheel switches. The sweep may be calibrated in terms of energy for further peak identification.

In the "EXPAND" mode the sweep is triggered at the beginning of the region of interest (XXXX for counter "B"), and the sweep speed may be increased to expand that portion of the spectrum as desired.

\section{VERTICAL DISPLAY}

The range switch shown in Figure 2 is marked "VERTICAL" (see Figure 1) and has 8 positions. This switch sends binary-coded control information to 10 one-of-eight demultiplexers (DEMUX) as shown in Figure 3. The first two inputs to the 10 DEMUX chips 


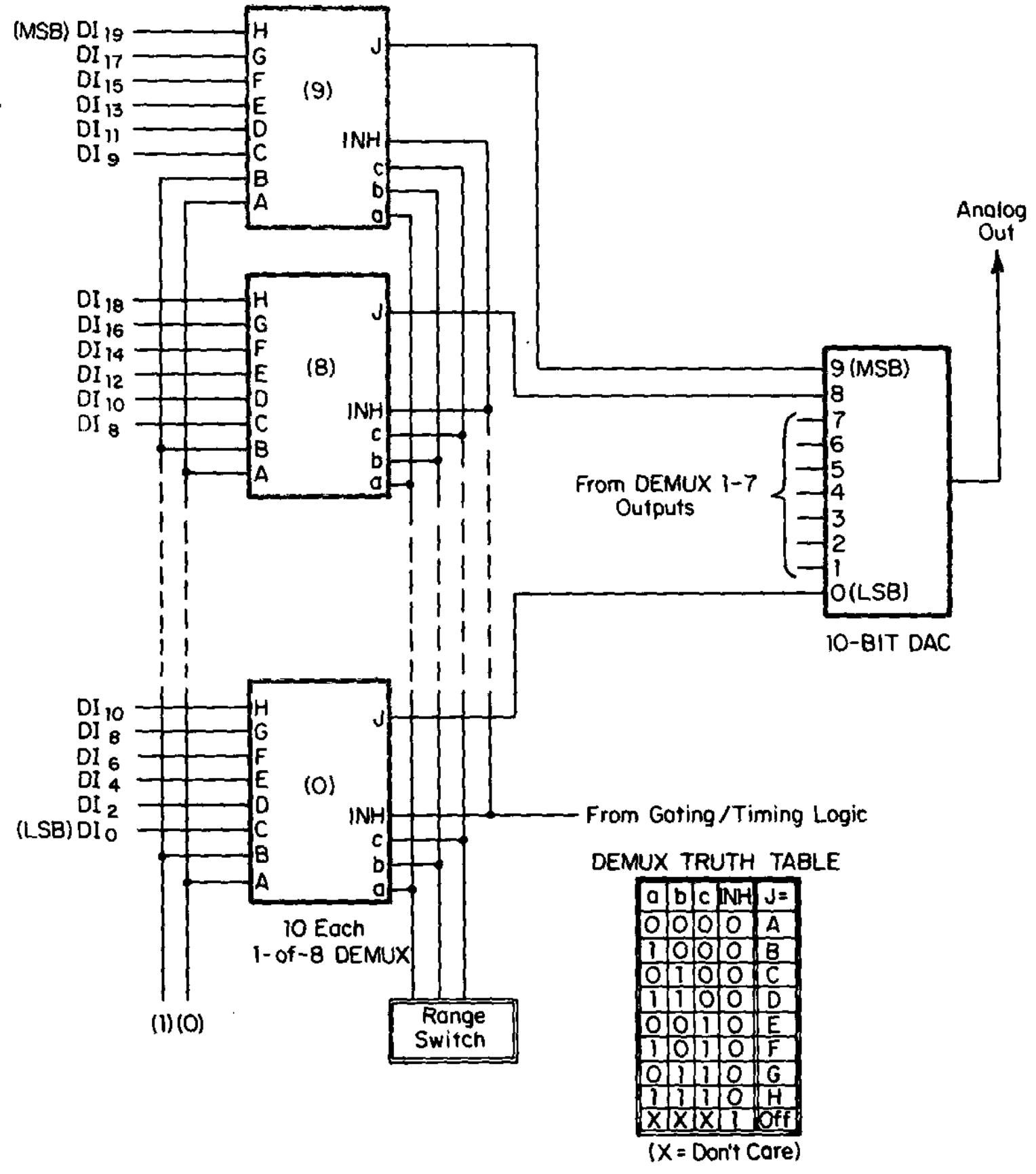

FIgURE 3. Demultiplexer-DAC, Simplified Diagram 
are connected to logic low and high, respectively. The first two range positions ("CAL: ZERO, FULL SCALE") connect the 10 DAC inputs to these for calibration; i.e., all bits low yield zero analog output and all bits high yield full scale output. The scope vertical gain may be adjusted as desired using these extremes for reference.

The remaining switch positions connect the DAC (via the DEMUXs) to 10 data input bits at a time $\mathrm{DI}_{0}$ through $\mathrm{DI}_{9}, \mathrm{DI}_{2}$ thru DI $11, \ldots-I_{10}$ thru $\left.D_{19}\right)$ in 6 steps. Switch positions are marked "COUNTS FULL SCALE: $1 \mathrm{~K}, 4 \mathrm{~K}, \cdots-10^{8} . "$ It should be noted that counts in excess of full scale may appear on screen as a split image. Adjusting the range switch will correct this if the total does not exceed the maximum range.

\section{BATTERIES}

An instrument was also designed for recharging the interface unit's batteries (Figure 4). Charging is accomplished by feeding a constant current of 150 ma to the batteries until their series voltage reaches $14.4 \mathrm{v}$, then switching to constant $\mathrm{mA}$ to the batteries and an indicator diode in paralle1. As battery charge increases the float voltage of 13.2 is reached and maintained indefinitely.

The power switch (Fig. 1) has 4 positions: "OFF," where batteries and external source are disconnected; "INT. BATT.," where only the batteries are connected to the load; "EXT. CHG.," where batteries and load are connected to the external charging source; and "CHG. ONLY," where the load is disconnected but the battery is connected to the charging source. A small light-emitting diode indicates when the external charger is supplying current, and a meter indicates battery terminal voltage in all but the "OFF" switch positions. An auxiliary switch disconnects the batteries when the instrument case is closed to prevent inadvertent discharge.

The two $6-v$ batteries are series connected, and are easily accessible behind a removable cover on the panel.

\section{PERFORMANCE OF THE INTERFACE DEVICE}

The prototype PHA/oscilloscope interface has been operated at SRL in laboratory and field service for approximately one year. Although operation has been satisfactory, it has been noted that switching noise in the DAC's analog output creates a background glow on the oscilloscope screen at normal brightness settings. 


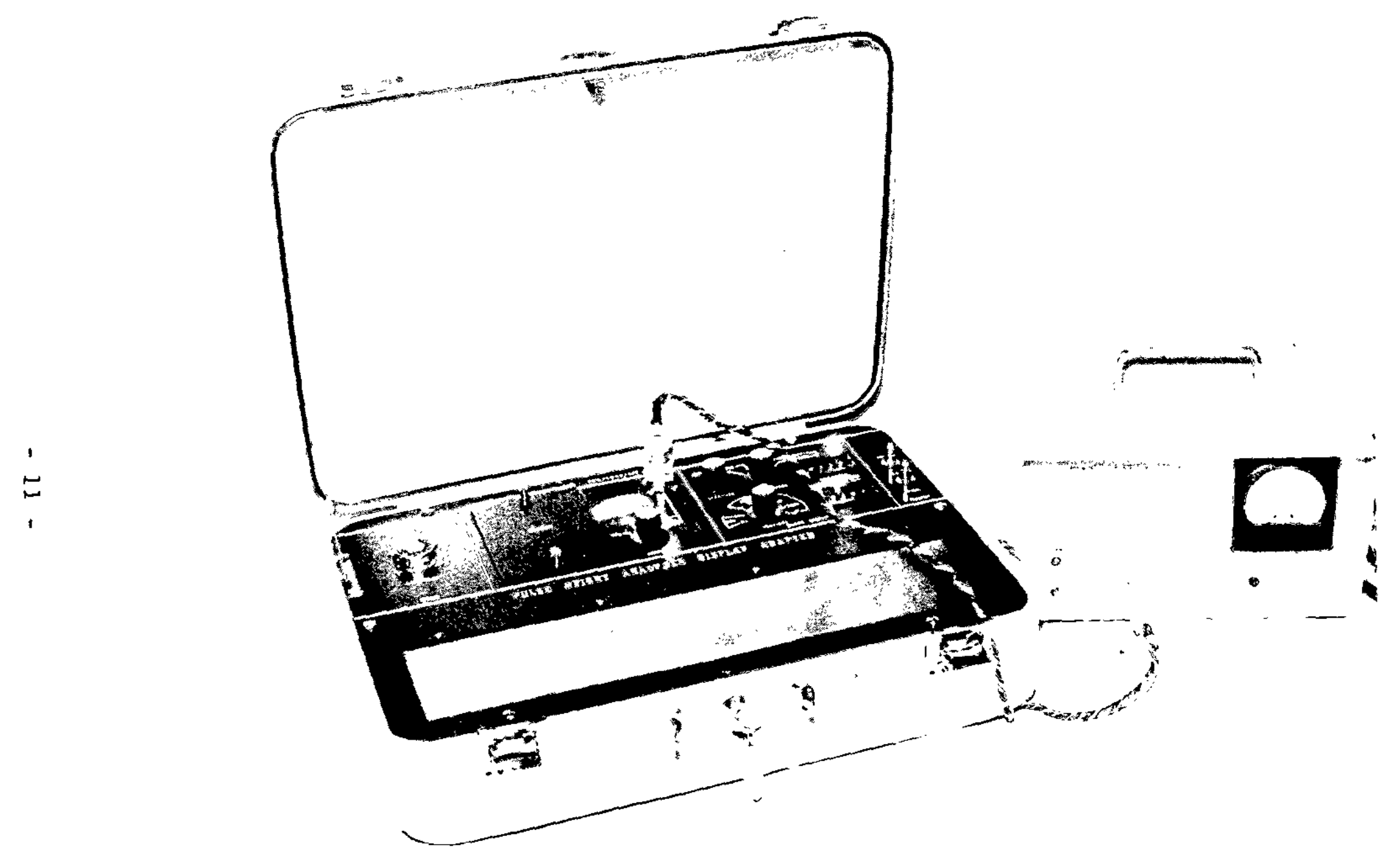

FIGURE 4. Instrument with Battery Charger Connected 
This glow appears as a band about the viewed spectrum, the width of which depends on scope vertical gain and interface range settings. The background band does not diminish effectiveness or readability of the display; however, future models will be designed to eliminate this noise.

Also, when the displayed spectrum represents near zero on the vertical axis, the "INTENSITY" mode of operation loses its effectiveness because alternate sweeps cover essentially the same trace. This does not present a problem because that mode of operation is not normally used except when it is desired to locate one region of interest amid other data-containing channels.

The instrument has been used with Phillips, Telequipment, and Tektronix oscilloscopes. Its operation has been trouble-free.

\section{REFERENCES}

1. J. S. Byrd and M. H. Goosey, "A Pu1se Height Analyzer with Automatic Deadtime Correction." Nuclear Instruments and Methods, to be published.

2. J. S. Byrd, "A Microprocessor-based Controller for Nuclear Instruments." IEEE Transaction on Nuclear Science, Oct. 1978. 